\title{
The Internal Stress Analysis Method of Cement Paste under Core Restricted Conditions
}

\author{
Y. Li, X.F. Liu, W.L. Bai \\ The Key Laboratory of Urban Security and Disaster Engineering \\ MOE \\ Beijing Key Lab of Earthquake Engineering and Structural Retrofit \\ Beijing University of Technology \\ Beijing, 100124, China
}

\begin{abstract}
Concrete cracking is a major cause affecting the durability and applicability of concrete; it draws increasing attention from researchers in the field of civil engineering. However, previous studies of early micro-cracks are insufficient. The presence of early micro-cracks is the basis of macroscopic cracks. Therefore, a calculation method of internal stress within cement paste caused by core restricted shrinkage under the core restricted condition of rigid body was studied, and a mechanical model of internal stress was established. Based on the model, the factors that affect internal stress within cement paste were further analyzed, and the law of strain variation of cement paste under the rigid elastic body confinement was discussed. The results show practical significance in the control of crack development and in the improvement of concrete durability.
\end{abstract}

Keywords-large elastic body; micro-crack; internal stress; elastic mechanics; model

\section{INTRODUCTION}

Shrinkage cracking is a issue which has gotten more and more attention in the field of civil engineering. With the rapid development of the modern concrete technique, including the use of the admixture, mineral addictive, low water-gel ratio and pump concrete with better performance, it widely increases the possibility of the generation of cracks. Structures using concrete with cracks will greatly reduce its working performance, including applicability and durability. Focusing on concrete structures with cracks during their working time, previous studies include: To solve this practical problem, a technique was developed to determine shrinkage stresses by using rubber models, and a new ring test was designed for the crack resistance of concrete (Carlson R.et al., 1988). In addition, state-of-the-art research on mechanisms was reviewed which caused complex cracking and newly developed methodologies to control cracking at early stage (Mihashi H. et al., 2004). Some tests were designed to simulate restrained shrinkage cracking by using a ring-type specimen, and a theoretical model was developed (Grzybowski M. et al., 1990). J-H Moon (2006) established the strain formulas of autogenously shrinkage and restricted shrinkage that correlate with relative humidity and property parameters of concrete by using the restrained ring. Additionally, according to the comparison of finite element analysis software, restricted classification was studied, and the influence of materials type on shrinkage cracking was investigated.
In the restrained shrinkage experiment, a steel ring enveloped by concrete is created, within which hoop stress arise to restrict the shrinkage of concrete. The restrained ring test has recently become a popular method to assess a mixture's susceptibility to retrained shrinkage cracking (Krause et al., 1995; Grzybowski 1989; Lim et al., 1999). Shah (1992) has verified that the free shrinkage of the restrained shrinkage ring is the same with the axial restrained one. As of now, many experiments and methods have been conducted to reduce concrete cracking. However, there has been no simpler integrated calculation model with respect to stress field which generates micro-cracks. There has not been enough corresponding theoretical direction, either.

In this paper, aggregates and unhydrated cement particles were simplified as rigid body, because their elasticity module was considerably larger than the hydration products around them. Thus, theoretical formulas and calculation method about the internal stress in cement paste under the core restriction of large elastic modulus body (aggregates and unhydrated cement particles) were established in this paper. Then, the factors that affect internal stress in cement paste were analyzed by the formulas, and micro-cracks can be reduced by changing environmental factors and material parameters.

\section{EXPERIMENTATION}

When the fresh cement paste began to harden, the dry shrinkage of volume occurs. With the increase of age, cement paste is restricted by rigid bodies (such as unhydrated cement particles, aggregates, and rebar). Additional strain occurs due to the restraint effect of internal rigid bodies, which can be taken as $\varepsilon=\varepsilon(\rho)$. In order to simplify the case, the radical displacement of the cementitious material, and an axisymmetric mechanical model of cement paste under the core restricted conditions are shown in Figure 1. An element of elastomer is taken and analyzed by means of equilibrium condition and polar coordinates, as shown in Figure 2. In this work, self-weight of cement paste, inertia force and the nonlinear properties of the cement paste are not taken into account. Referring to the restrained shrinkage experiment of steel ring, the paper took the stress in single plane of concrete into consideration and the concrete ring was simply under the stress along the direction of ring and radial, plane axisymmetric assumption fulfilled. Thus, the model is a case of axisymmetric plane strain. 


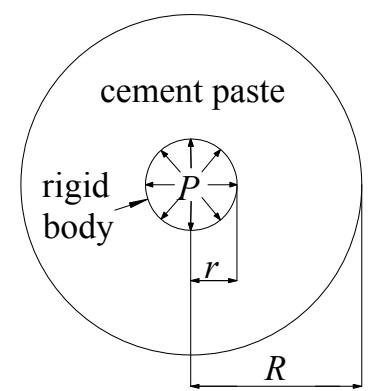

FIGURE I. THE MECHANICAL MODEL OF CEMENT PASTE.

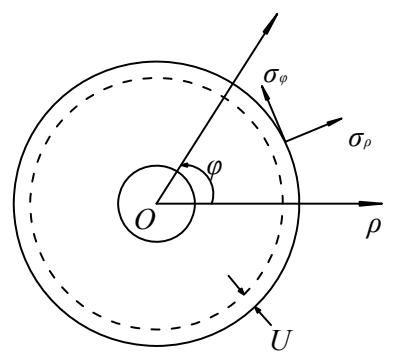

FIGURE II. THE MODEL IN POLAR COORDINATES.

Where, $\rho$ and $\varphi$ denote the coordinate direction, $U$ $(\times 10-3 \mathrm{~mm})$ is the radial displacement, and $\varphi$ is the circumferential displacement.

Thus, the internal stress becomes:

$\left\{\begin{array}{l}\sigma_{\rho}=A\left[\frac{2}{3}\left(1-\frac{3}{4} m\right) \frac{r}{\rho^{2}}+m \cdot \ln \frac{\rho}{r} \cdot \frac{r}{\rho^{2}}-\frac{1}{\rho}+\frac{\rho}{3 r^{2}}+\frac{m}{2 r}\right]-\left(\frac{1}{r^{2}}-\frac{1}{\rho^{2}}\right) \cdot A \cdot B-2\left(1-\frac{m^{2} r^{2}}{\rho^{2}}\right) \cdot A \cdot C \\ \sigma_{\varphi}=-A\left[\frac{2}{3}\left(1-\frac{3}{4} m\right) \frac{r}{\rho^{2}}+m \cdot \ln \frac{\rho}{r} \cdot \frac{r}{\rho^{2}}-\frac{1}{\rho}+\frac{\rho}{6 r^{2}}+\frac{m}{2 r}\right]-\left(\frac{1}{r^{2}}+\frac{1}{\rho^{2}}\right) \cdot A \cdot B-2\left(1+\frac{m^{2} r^{2}}{\rho^{2}}\right) \cdot A \cdot C \\ +A\left(\frac{m r}{\rho^{2}}-\frac{1}{\rho}+\frac{\rho}{2 r^{2}}+\frac{m}{r}\right)\end{array}\right.$

Where,

$$
\begin{gathered}
\mathrm{A}=\frac{\mathrm{E} \cdot \mathrm{U}}{\left(1-v^{2}\right) \cdot\left(\mathrm{m}^{2}-1\right)} \\
\mathrm{B}=\frac{\mathrm{m}\left(\ln \mathrm{m}-\frac{3}{2}\right)+\frac{1}{6}\left(5 \mathrm{~m}^{3}+4\right)}{\mathrm{m}^{2}-1} \cdot \mathrm{r} \\
\mathrm{C}=\frac{(1-v) \cdot\left[m\left(\ln m-\frac{3}{2}\right)+\frac{1}{6}\left(5 m^{3}+4\right)\right]}{\left(m^{2}-1\right) \cdot\left[(2 v-1) \cdot\left(m^{2}-1\right) k+(2 v-1)-m^{2}\right] \cdot r} \\
\mathrm{k}=\frac{E}{E} \\
\mathrm{R}=\frac{m}{m} \cdot r
\end{gathered}
$$

where, $\sigma_{\rho}(\mathrm{GPa})$ represents the radial normal stress in the direction of $\rho, \sigma_{\varphi}(\mathrm{GPa})$ represents the circumferential normal stress in the direction of $\varphi, \varepsilon_{\rho}$ is the radial linear strain, $\varepsilon_{\varphi}$ is the circumferential linear strain, $v$ is the passion ration, and $E$ and $E^{\prime}$ are the elastic modulus of the cement paste and the rigid body, respectively.

\section{EXPERIMENTAL RESULTS}

In order to verify the formulas above, the microstructure of the model of cement paste was examined by imaging the interfacial transition zone between the aggregate and the hydration products in a scanning electron microscope (SEM, FEI Quanta 200, Holland). The parameters of SEM were listed below: the accelerating voltage is $200 \mathrm{~V} \sim 30 \mathrm{KV}$, the magnifying power is $\mathrm{X} 25 \sim \mathrm{X} 200000$, and the distinguishability is $3.5 \mathrm{~nm}$. In order to gather the first image, the specimen was put into the SEM for $60 \mathrm{~min}$ with $80 \%$ of relative humidity.

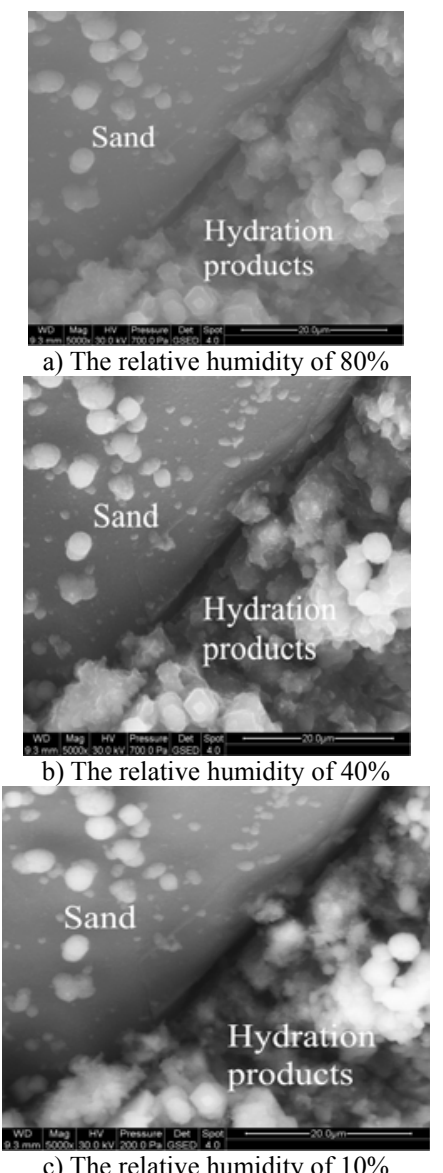

FIGURE III. MICROGRAPHS OF CEMENT PASTE FOR VARIOUS RELATIVE HUMIDITY.

Figure 3 shows that sand was enclosed in the hydration products, which is as same as the microstructure of Figure 1. It can be seen that, with the decrease in relative humidity, the hydration products begins to shrink. Under the restriction of sand, the radial and hoop stress exerted on hydration products result in the increasing gap between sand and hydration products. Then, to find the laws which cracks obey, the relative humidity in the concrete is specified by the corresponding parameters in the Equation1.

Under the condition of the same raw materials and curing environment, the variation law of the shrinkage cracking stress under the restraining of the rigid body was explained with the Equation1 and the micrographs from Figure 3. Meanwhile, under the same raw materials (Figure 3) and curing environment in a related experiment, using the nano-indentation method, the test results were calculated from the curve of the force to the indentation depth. The elastic modulus of the sand and the hydration products are 107.06 
$\pm 4.95 \mathrm{GPa}$ and $32.53 \mathrm{GPa}$, respectively. In order to calculate $\sigma_{\rho}$ and $\sigma_{\varphi}$ in Equation1, E and $\mathrm{E}^{\prime}$ were assumed as $33.58 \mathrm{GPa}$ and $110 \mathrm{GPa}$, respectively. $v$ and $v^{\prime}$ were assumed as 0.28 and 0.17 , respectively. $U$ was assumed as $-0.04 \times 10-3 \mathrm{~mm}$. Then, $\mathrm{k}=0.305, \mathrm{~m}=10$. And Table 1 lists the results of circumferential normal stress of Equation1.

TABLE I. THE RESULTS FROM EQUATION1.

\begin{tabular}{|c|c|c|c|c|c|c|}
\hline \multirow[b]{2}{*}{ NO. } & \multicolumn{2}{|c|}{$\mathrm{r}=1 \mathrm{~mm}$} & \multicolumn{2}{|c|}{$\mathrm{r}=2 \mathrm{~mm}$} & \multicolumn{2}{|c|}{$\mathrm{r}=3 \mathrm{~mm}$} \\
\hline & $\begin{array}{l}\rho \\
(\mathrm{mm})\end{array}$ & $\begin{array}{l}\sigma_{\varphi} \\
(\mathrm{MPa})\end{array}$ & $\begin{array}{l}\rho \\
(\mathrm{mm})\end{array}$ & $\begin{array}{l}\sigma_{\varphi} \\
(\mathrm{MPa})\end{array}$ & $\begin{array}{l}\rho \\
(\mathrm{mm})\end{array}$ & $\begin{array}{l}\sigma_{\varphi} \\
(\mathrm{MPa})\end{array}$ \\
\hline 1 & 3 & 2.64 & 5 & 2.05 & 10 & 1.86 \\
\hline 2 & 4 & 2.81 & 6 & 2.64 & 11 & 1.89 \\
\hline 3 & 5 & 2.54 & 7 & 2.82 & 12 & 1.88 \\
\hline 4 & 6 & 2.14 & 8 & 2.81 & 13 & 1.83 \\
\hline 5 & 7 & 1.68 & 9 & 2.71 & 14 & 1.77 \\
\hline 6 & 8 & 1.20 & 10 & 2.54 & 15 & 1.70 \\
\hline
\end{tabular}

In Table 1 , the circumferential normal stress $\left(\sigma_{\varphi}\right)$ from Equation1 with different diameters of the rigid body are between $1 \mathrm{MPa}$ and $3 \mathrm{MPa}$, and interrelated test was about the tensile stress test of cement paste with different mineral admixture, and the result indicated that the tensile stress was 1 3 MPa (Li Y., Yan Q.,2012), which was in accord with the calculation results obtained by the model formula to some extent. Thus if, the parameters of the Equation1 are changed, the value of the shrinkage stress can be in control. Therefore, it's effective to control the cracks of the cement paste with the changed mineral admixtures and changed relative humidity.

\section{CONCLUSIONS}

(1)A theoretical model for the internal stress analysis of cement paste under core restricted conditions was established based on the elastic mechanics and the restrained shrinkage experiment.

(2)According to this model, the main factors that influence the cracks were further analyzed. By using testing results of various components in hydrated cement paste and some assumptions, the parameters in the model are determined and internal stress were calculated.

(3)With the results from Equation1, the parameters of Equation 1 can be changed, and then the value of the shrinkage stress can be in control to some extent.

(4)With the results from Equation1, it's effective to control the cracks of the cement paste with the changed mineral admixtures and changed relative humidity.

\section{ACKNOWLEDGMENTS}

The authors would like to acknowledge the financial support provided by Program for New Century Excellent Talents in University (NCET-12-0605); The Importation and Development of High-Caliber Talents Project of Beijing Municipal Institutions (CIT\&TCD20150310); National Natural Science Foundation of China (51278014).

\section{REFERENCE}

[1] Carlson R W, Reading T J. Model study of shrinkage cracking in concrete building walls[J]. ACI Structural Journal, 1988, 85(4), 395-404.

[2] Mihashi H, Leite J P B. State-of-the-art report on control of cracking in early age concrete[J]. Journal of Advanced Concrete Technology, 2004, 2(2): 141-154.
[3] Grzybowski M, Shah S P. Shrinkage cracking of fiber reinforced concrete[J]. ACI Materials Journal, 1990, 87(2). 138-148.

[4] Moon J H. Shrinkage, residual stress, and cracking in heterogeneous materials[M]. ProQuest, 2006.

[5] Krause, P. D., Rogalla, E A., Sherman, M. R, Mcdonald, D. B., ,et al.(1995), "Transverse Cracking in Newly Constructed Bridge Decks", NCHRP380, Project 12.37.

[6] Grzybowski, M., (1989a), "Determination of Crack Arresting Properties of Fiber Reinforced Cementitious Composites", Ph.D. Thesis, Royal Institute of Technology, Stockholm, Sweden.

[7] Lim, Y.M., H.C. Wu and V.C. Li, (1999), "development of Flexural Composite Properties and Dry Shrinkage Behavior of High Performance Fiber Reinforced Cementitious Composites at Early Age", J. of Materials, Vol.96, NO.1, American Concrete Institute, pp.20-26.

[8] Shah S.P Effect of shrinkage-reducing admixtures on restrained shrinkage cracking of concrete. ACI Material Journal, 1992,89(3).

[9] Tazawa E, Miyazawa S. Experimental study on mechanism of autogenous shrinkage of concrete[J]. Cement and Concrete Research, 1995, 25(8): 1633-1638.

[10] Li Y, Yan Q, Du X. Relationship between Autogenous Shrinkage and Tensile Strength of Cement Paste with SCM[J]. Journal of Materials in Civil Engineering, 2012, 24(10): 1268-1273.

[11] Qianqian Yan. Properties Research of Early-age Shrinkage and Crack of the Cementitious materials. Beijing: Beijing University of Technology, 2012 . 